\title{
A clinical and etiological spectrum of thrombocytopenia in adult patients
}

\author{
Gamit M. ${ }^{\mathbf{1}}$, Rathod G. ${ }^{\mathbf{2}}$ \\ DOI: https://doi.org/10.17511/jopm.2020.i06.02 \\ 1 Mital Gamit, Assistant Professor, Department. of Pathology, GMERS Medical College, Vadnagar, Gujarat, India. \\ 2* Gunvanti Rathod, Associate Professor, Department of Pathology, GMERS Medical College, Ahmedabad, Gujarat, India.
}

Introduction: Thrombocytopenia is not a disease but is a diagnosis. The detailed knowledge must be acquired from patients who have thrombocytopenia. This study aimed to determine the relative frequency of different disease conditions presenting as newly found thrombocytopenia in adult patients and to determine whether a low platelet count or presence of bleeding manifestation was considered more often as an indicator for platelet transfusion. Materials and Methods: This retrospective study was done at a tertiary care hospital during the period of November 2018 to October 2019. Blood samples were analyzed for Complete Blood Count (CBC). The clinicopathological correlation was done and the findings were tabulated. Results: In present study, the sex distribution of patients of thrombocytopenia was noted as $55.75 \%$ male and $44.25 \%$ female. The present study showed that most of the cases of thrombocytopenia belonged to the age group of $18-29$ years $(45 \%)$, followed by the age group of $30-39$ years $(28.75 \%)$, the least being in the age group of over 80 years $(2.0 \%)$. Most of the patients presented with Grade 1 thrombocytopenia $(49.5 \%)$. The most common etiology responsible for newly diagnosed thrombocytopenia in adult patients was found to be dengue/dengue-like fever (41.75\%). Conclusion: It can be concluded from this study that the most common causes for thrombocytopenia are infective causes e.g. dengue, malaria.

Keywords: Thrombocytopenia, Dengue, Malaria, Complete Blood Count

Corresponding Author

Gunvanti Rathod, Associate Professor, Department of Pathology, GMERS Medical College, Ahmedabad, Gujarat, India.

Email: neempath@gmail.com
How to Cite this Article

To Browse

Gamit M, Rathod G. A clinical and etiological spectrum of thrombocytopenia in adult patients. Trop J Pathol Microbiol. 2020;6(6):377-380.

Available From

https://pathology.medresearch.in/index.php/jopm/ar ticle/view/467

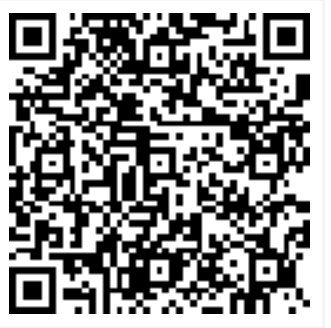

Review Round 2 2020-08-15 2020-07-08

Conflict of Interest No
Review Round 1 2020-07-26

Funding
Ethical Approval Yes
Review Round 3

Plagiarism X-checker $6 \%$
Accepted 2020-08-26

Note

(C) 2020 by Mital Gamit, Gunvanti Rathod and Published by Siddharth Health Research and Social Welfare Society. This is an Open Access article licensed under a Creative Commons Attribution 4.0 International License https://creativecommons.org/licenses/by/4.0/ unported [CC BY 4.0]. 


\section{Introduction}

Platelets are essentially fragments of the megakaryocyte cytoplasm. In day to day practice, the normal platelet count is $1.5 \mathrm{lac}-3.5 \mathrm{lac} / \mathrm{cmm}$. Thrombocytopenia is not a disease but is a diagnosis that means a reduction in platelet count. Three major pathophysiological mechanisms in thrombocytopenia are decreased platelet production, increased platelet destruction or consumption, or increased splenic sequestration (capturing of circulating platelets in the spleen). Recently fever with thrombocytopenia is a common clinical presentation in tertiary-care hospitals. Established infective causes such as dengue are well known for fever with thrombocytopenia. Malaria is a common infection in most parts of India and is commonly associated with mild thrombocytopenia [1]. Severe thrombocytopenia is common in isolated falciparum and mixed falciparum/vivax malaria. Detailed examination and laboratory tests should be done, which are related to etiology. This study aimed to determine the relative frequency of different disease conditions presenting as newly found thrombocytopenia in adult patients.

\section{Materials and Methods}

The present retrospective study was done in the Hematology section, Pathology Department of tertiary care hospital, during the period of November 2018 to October 2019. The Ethics Committee approval was taken from the institute and after that only the study was conducted.

Inclusion criteria: All the patients who were having thrombocytopenia and age more than 18 years were included in the study.

Exclusion criteria: All the patients who were having age below 18 years were excluded from the study.

Sample collection: Blood samples from the patients were collected and analyzed for Complete Blood Count (CBC) on Horiba 5 part differential fully automatic cell counter.

Data collection method: All the patients with platelet count less than $150 \times 103 / \mu \mathrm{L}$ and confirmed on peripheral blood smear were included in the present study. The clinical history of the patients was traced with a focus on finding the etiological correlation. On the basis of platelet count, the cases were divided into the four following grades:
ML (microlitre)

Grade 1: $75-150 \times 103 / \mu \mathrm{L}$

Grade 2: $50-75 \times 103 / \mu \mathrm{L}$

Grade 3: $25-50 \times 103 / \mu \mathrm{L}$

Grade 4: $<25 \times 103 / \mu \mathrm{L}$

Repeat platelet counts were done in subjects with marked thrombocytopenia until normal or nearnormal values were reached. The bleeding manifestations that the patients presented with or developed during their course in the hospital were recorded. The diagnosis made in each of these cases was noted down. The proportion of patients receiving platelet transfusion because of the presence of bleeding manifestations and those requiring prophylactic platelet transfusions were determined. The clinicopathological correlation was done and the findings were tabulated. The statistical analysis was done by SPSS and the data was expressed.

\section{Results}

A total of 400 cases of thrombocytopenia were noted in adult patients with a sex distribution of $55.75 \%$ male and $44.25 \%$ female (Table-1). In the present study, it was found that infectious cause was the most common for thrombocytopenia. According to Table-2, the most common etiology responsible for newly diagnosed thrombocytopenia in adult patients was found to be dengue/denguelike fever $(41.75 \%)$ followed by malaria $(26.50 \%)$, chronic liver disease 58 (14.5\%), septicemia (7.25\%), aplastic anemia (2\%), DIC (4.25\%) and other causes $(3.75 \%)$.

In the present study, most patients presented with Grade 1 thrombocytopenia (49.5\%) followed by Grade $2(22 \%)$, Grade $3(19.75 \%)$, and Grade 4 thrombocytopenia $(8.75 \%)$ with platelet count as low as $2000 / \mu \mathrm{L}$ noted in a case of aplastic anemia (Table-3).

Table-1: Age and sex distribution.

\begin{tabular}{|l|l|l|l|l|}
\hline \multirow{2}{*}{ Age groups (Years) } & \multicolumn{3}{|c|}{ No. of cases } & \multirow{2}{*}{ Percentage (\%) } \\
\cline { 2 - 4 } & Male & Female & Total & \\
\hline $18-29$ & 98 & 82 & 180 & 45 \\
\hline $30-39$ & 80 & 55 & 135 & 28.75 \\
\hline $40-59$ & 38 & 29 & 77 & 19.25 \\
\hline $60-79$ & 12 & 08 & 20 & 5.0 \\
\hline Over 80 & 05 & 03 & 08 & 2.0 \\
\hline Total & 223 & 177 & 400 & 100 \\
\hline
\end{tabular}


Table-2: Causes of thrombocytopenia in the present study.

\begin{tabular}{|l|l|l|}
\hline \multicolumn{1}{|c|}{ Cause } & No. of cases & \multicolumn{1}{c|}{ Percentage (\%) } \\
\hline Dengue & 167 & 41.75 \\
\hline Malaria & 106 & 26.50 \\
\hline Chronic liver disease & 58 & 14.50 \\
\hline Septicemia & 29 & 7.25 \\
\hline Aplastic anemia & 08 & 2.00 \\
\hline DIC & 17 & 4.25 \\
\hline Other causes & 15 & 3.75 \\
\hline Total & 400 & 100 \\
\hline
\end{tabular}

Table-3: Severity of thrombocytopenia.

\begin{tabular}{|l|l|l|}
\hline \multicolumn{1}{|c|}{ Grade } & \multicolumn{1}{c|}{ No. of cases } & \multicolumn{1}{c|}{ Percentage (\%) } \\
\hline Grade 1 (75-150) & 198 & 49.5 \\
\hline Grade 2 (50-75) & 88 & 22.0 \\
\hline Grade 3 (25-50) & 79 & 19.75 \\
\hline Grade 4(<25) & 35 & 8.75 \\
\hline Total & 400 & 100 \\
\hline
\end{tabular}

\section{Discussion}

The present study aimed to know the modes of clinical presentations and possible causes of thrombocytopenia. This study might help us to correlate the clinical features and laboratory findings to come to a conclusion regarding the possible infective causes for thrombocytopenia and thus diagnosis and management.

The distribution of patient according to age and sex were similar to a study at conducted over 4 months by Lakdum, et al. [2]. In their study, a total of 500 patients were studied on fever with thrombocytopenia in which $65.2 \%$ were male and $34.8 \%$ were female respectively.

The present study showed that most of the cases of thrombocytopenia belonged to the age group of 1829 years $(45 \%)$, followed by the age group of $30-39$ years $(28.75 \%)$, the least being in the age group of over 80 years $(2.0 \%)$.

Among all causes, dengue (41.75\%) was the commonest cause of thrombocytopenia that correlated with the study by Bhalara, et al. [3]. The cause for this variation may be due to seasonal and regional variations. Dengue virus has been isolated from polymorphonuclear (PMN) leukocytes, monocyte/ macrophages, dendritic cells, and others [4]. It has also been detected in megakaryocyte progenitors and circulating platelets [5-7].

The two mechanisms probably involved in dengueinduced thrombocytopenia are impaired thrombo-
Poiesis and peripheral platelet destruction. The second common cause of thrombocytopenia in the present study was malaria (26.50\%). Thrombocytopenia is a common feature of both falciparum and vivax malaria. As seen in the present study as well, thrombocytopenia is a diagnostic clue to the presence of malaria [8]. The frequency of thrombocytopenia (i.e. platelet count below $150,000 / \mathrm{mm} 3$ ) in malaria infection ranges from 24$94 \%$ in the literature [9]. It is postulated that the cause of thrombocytopenia is most probably due to the binding of malarial antigens to the surface of platelets that cause antimalarial antibodies to additionally bind to the platelets, leading to the in situ formation of immune complexes (ICS) [10].

The fall of platelet count is independent of age, duration of illness, spleen size, and parasite count [11]. Chronic liver disease was found in 58 (14.5\%) patients, which causes persistent thrombocytopenia and manifests as cirrhosis, fibrosis, and portal hypertension. Septicemia (7.25\%) was another cause of infections with common viruses including hepatitis B and C, HIV, Epstein-Barr virus, cytomegalovirus, varicella-zoster virus, rubella, and mumps. In the present study, DIC caused $4.25 \%$ of the causes of thrombocytopenia.

DIC can result from severe infections, as a complication of pregnancy or labor, high blood pressure, and preeclampsia. The least number of cases were of Aplastic anemia (2\%) causing thrombocytopenia. Other causes of thrombocytopenia e.g. hypersplenism, ITP, etc contributed $3.75 \%$ of cases in the present study.

In the present study, most patients presented with Grade 1 thrombocytopenia (49.5\%) followed by Grade 2 (22\%), Grade 3 (19.75\%), and Grade 4 thrombocytopenia (8.75\%). These findings could not be correlated with other studies in which, the range for mild, moderate, and severe thrombocytopenia were different as there are no uniformly accepted criteria for the grading of thrombocytopenia.

\section{Conclusion}

It can be concluded from this study that the most common causes for thrombocytopenia are infective causes e.g. dengue, malaria. This is the reason why there is a strong need to take action for prevention of the mosquito-borne disease in our country. The government should take initiative to irradiate such disease through various national programs. 


\section{What does this study add to the existing knowledge}

There is a scarcity of literature on thrombocytopenia, which is the most common finding in a clinicopathological setup. Especially in developing countries such as India, during monsoons there is a rapid surge of cases of thrombocytopenia, sometimes leading to fatal consequences due to bleeding episodes. Therefore especially for pathologists keeping in mind the most common causes of thrombocytopenia will identify the patients at risk and helpful for the reduction in mortality and morbidity related to thrombocytopenia.

\section{Author's contribution}

Dr. Mital Gamit and Dr. Gunvanti Rathod were actively involved in sample collection, data collection, processing of collected data, and overall work related to preparing the manuscript of this study.

\section{Reference}

01. Rathod GB, Parmar P. Study of association of thrombocytopenia with plasmodium vivax infection. Indian J Med Sci. 2017;69(1)33-35. doi: 10.18203/issn.00195359.IndianJMedSci20170489 [Crossref]

02. Naikwadi AM, Anjum SN. Study of Clinical and Laboratory Profile of Fever with Thrombocytopenia in Tertiary Hospital. Int J Contemp Med Res. 2019;6(7)556-61. doi: 10.21276/ijcmr.2019.6.7.21 [Crossref]

03. Bhalara SK, Shah S, Goswami H, Gonsai RN. Clinical and etiological profile of thrombocytopenia in adults- A tertiary-care hospital-based cross-sectional study. Int J Med Sci Public Health. 2015;4(1)7-10.

doi: 10.5455/ijmsph.2015.060920141 [Crossref]

04. Srikanth J, Srinivas S, Krishna CR, Ramulu PR. Prevalence of thrombocytopenia in a diagnosed case of malaria in rural population of South India. J NTR Univ Health Sci. 2012;1(3)152155.

doi: $10.4103 / 2277-8632.102438$ [Crossref]
05. Onlamoon N, Noisakran S, Hsiao HM, Duncan A, Villinger $F$, Ansari $A A$, et al. Dengue virusinduced haemorrhage in a nonhuman primate model. Blood, 2010;115(9)1823-1834. doi: 10. 1182/blood-2009-09-242990 [Crossref]

06. Nakao S, Lai CJ, Young NS. Dengue virus, a flavivirus, propagates in human bone marrow progenitors and hematopoietic cell lines. Blood. $1989 ; 74(4) 1235-1240$.

[Crossref]

07. Noisakran $S$, Gibbons RV, Songprakhon $P$, Jairungsri A, Ajariyakhajorn C, Nisalak A, et al. Detection of dengue virus in platelets isolated from dengue patients. Southeast Asian J Trop Med Public Health. 2009;40(2)253-262. [Crossref]

08. Saito M, Oishi K, Inoue S, Dimaano EM, Alera MT, Robles AM, et al. Association of increased platelet-associated immunoglobulins with thrombocytopenia and the severity of disease in secondary dengue virus infections. Clin Exp Immunol. 2004;138(2)299-303.

doi: $10.1111 /$ j.1365-2249.2004.02626.x [Crossref]

09. Skudowitz RB, Katz J, Lurie A, Levin J, Metz J. Mechanisms of thrombocytopenia in malignant tertian malaria. Br Med J. 1973;2;515-518. doi: $10.1136 / \mathrm{bmj} .2 .5865 .515$ [Crossref]

10. Gallup JL, Sachs JD. The economic burden of malaria. Am J Trop Med Hyg. 2001;64(1-2)8596.

[Crossref]

11. Kelton JG, Keystone J, Moore J, Denomme G, Tozman $E$, Glynn $M$, et al. Immune-mediated thrombocytopenia of malaria. J Clin Invest. $1983 ; 71(4) 832-836$. doi: $10.1172 /$ jci110836 [Crossref] 